\title{
REDUCTION IN THE SEVERITY OF MYCOPLASMA PNEUMONIAE-INDUCED PNEUMONIA IN HAMSTERS BY IMMUNOSUPPRESSIVE TREATMENT WITH ANTI- THYMOCYTE SERA
}

\author{
Geraldine Taylor, D. Taylor-Robinson and G. W. Fernald* \\ MRC Clinical Research Centre, Watford Road, Harrow, Middlesex HAI 3UJ, and \\ University of North Carolina,* Chapel Hill, NC, USA
}

\section{Plate XII}

THE pathogenesis of pneumonia in man caused by Mycoplasma pneumoniae is poorly understood. However, the $M$. pneumoniae-infected Syrian hamster is a useful model, not only because this is one of the few small animals that can be successfully infected, but also because the histological characteristics of the pneumonia and the temporal development of antibody are similar to these features in man (Dajani, Clyde and Denny, 1965; Fernald, 1969).

Pneumonia in hamsters infected with $M$. pneumoniae consists of peribronchial and perivascular cuffing by lymphocytes, and this suggests that it is the result of a delayed hypersensitivity response in the lung. However, immunoglobulin is associated with many of the cells (Fernald, Clyde and Bienenstock, 1972), indicating that the response may not be a pure delayed hypersensitivity reaction. Nevertheless, other observations suggest that delayed hypersensitivity develops during $M$. pneumoniae infection. Thus, guinea-pigs and man develop skin hypersensitivity (Fernald, 1971; Mizutani et al., 1971). Furthermore, lymphocytes from previously infected human subjects and guinea-pigs can be stimulated in vitro by $M$. pneumoniae antigens to undergo blast transformation (Leventhal et al., 1969; Fernald, 1971; Biberfeld, 1972; Fernald, 1972), and the migration of macrophages can be inhibited by $M$. pneumoniae antigen (Arai et al., 1971). Nevertheless, these in-vitro demonstrations of delayed hypersensitivity may not be relevant in vivo. However, with regard to the latter situation, Denny, Taylor-Robinson and Allison (1972) demonstrated that mice, immunosuppressed by thymectomy and X-irradiation and infected intranasally with $M$. pulmonis, developed lung lesions that were much less severe than those observed in infected but immunologically normal mice. Although the lung lesions in these mice and in $M$. pneumoniae-infected hamsters appear similar, this does not necessarily mean that thymusdependent mechanisms are also important in the development of hamster lung lesions.

Because we are particularly interested in the hamster as a model for the human disease, the effect of thymus-dependent lymphocyte depletion on the development of $M$. pneumoniae-induced lung lesions in hamsters was investigated. Immunosuppression was effected by the use of anti-thymocyte serum. The present report records findings obtained with this model in two laboratories.

\section{MATERIALS AND METHODS}

Mycoplasma pneumoniae strains. Virulent $M$. pneumoniae strains P1-104166, B8-M129 and P5-427A, known to produce pneumonia in hamsters were used. The mycoplasmas

Received 22 Oct. 1973; accepted 12 Dec. 1973.

J. MED, MICROBIOL.-VOL. 7 (1974) 
were grown in thallium acetate-free mycoplasma medium for seven days, dispensed in 1-ml amounts and stored at $-70^{\circ} \mathrm{C}$. Each $1-\mathrm{ml}$ portion contained $10^{6}$ colour-changing units (vide infra).

Infection and immunosuppression of hamsters. Golden, Syrian hamsters weighing approximately $100 \mathrm{~g}$ were supplied by Coombehurst in England and by Engle's Hamstery in the USA. The hamsters were anaesthetised by intraperitoneal inoculation of sodium pentobarbitone $(0.06 \mathrm{mg}$ per $\mathrm{g}$ body weight), and infected by intranasal inoculation of $0.2 \mathrm{ml}$ of the $M$. pneumoniae culture. As controls, other animals were given an equivalent intranasal inoculation of mycoplasma medium.

Hamsters were immunosuppressed by intraperitoneal inoculation of $0.002 \mathrm{ml}$ per $\mathrm{g}$ body weight of pig anti-hamster thymocyte serum (ATS) supplied by Dr A. C. Allison (Clinical Research Centre) or rabbit anti-hamster thymocyte serum prepared by one of us (G.W.F.). The pig ATS was made by intravenous inoculation of $5 \times 10^{9}$ hamster thymocytes on two occasions 14 days apart (Levey and Medawar, 1966). The rabbit ATS was prepared by inoculating $10^{8}$ thymocytes in complete Freund's adjuvant into the hind foot pads followed three weeks later by two intravenous injections, two days apart, of $10^{8}$ thymocytes. The animals were bled 1 week later. The pig ATS was heat-inactivated at $56^{\circ} \mathrm{C}$ for $30 \mathrm{~min}$. and absorbed with hamster erythrocytes before use; rabbit ATS was not heated or absorbed. The ATS was inoculated two days before infection with $M$. pneumoniae and daily thereafter until day 14 at which time the experiments were terminated. As controls, some hamsters were treated with normal pig or rabbit serum administered in the same way.

Mycoplasma medium. In both laboratories, liquid medium for isolation and growth of M. pneumoniae consisted of PPLO broth $70 \%(\mathrm{v} / \mathrm{v})$, unheated horse serum $20 \%(\mathrm{v} / \mathrm{v})$, yeast extract $10 \%(\mathrm{v} / \mathrm{v})$ of a $25 \%(\mathrm{w} / \mathrm{v})$ aqueous solution, glucose $0 \cdot 1 \%(\mathrm{w} / \mathrm{v})$, thallium acetate $0.05 \%(\mathrm{w} / \mathrm{v}), 1000$ units of penicillin $\mathrm{G}$ per $\mathrm{ml}$ and phenol red $0.002 \%(\mathrm{w} / \mathrm{v})$. The $p \mathrm{H}$ of the medium was adjusted to $\mathbf{7 \cdot 8}$.

Mycoplasma isolation and identification. Two weeks after intranasal inoculation of $M$. pneumoniae, namsters were killed by intraperitoneal injection of pentobarbitone and bleeding from the axillary vessels. Specimens from the pharynx were obtained by passing calcium-alginate-wool swabs deeply into the pharynx several times and then rinsing them in $1.8 \mathrm{ml}$ of mycoplasma medium. This was regarded as a 10-fold dilution of the specimen. At the Clinical Research Centre, lungs were irrigated with $4 \mathrm{ml}$ of medium to remove mycoplasmas, as described by Taylor-Robinson et al. (1972). At Chapel Hill, lungs were homogenised in mycoplasma medium to make a $10 \%(\mathrm{w} / \mathrm{v})$ suspension, and in both laboratories specimens of brain, liver and spleen were homogenised in the same way. The numbers of mycoplasmas present in the blood and various other specimens were determined by making serial ten-fold dilutions of the samples in $1.8-\mathrm{ml}$ volumes of medium contained in tightly capped vials. These were incubated at $37^{\circ} \mathrm{C}$ for at least 3 weeks, during which time they were observed for growth of mycoplasmas as indicated by a reduction in $p \mathbf{H}$ and consequent change in colour of the medium. The highest dilution then showing a change from pink to yellow was considered to contain one colour-changing unit (c.c.u.). Isolated organisms were identified as $M$. pneumoniae by the disk growth-inhibition technique (Clyde, 1964).

Histological procedures. Lungs were fixed in formol-saline. At the Clinical Research Centre, lungs were distended in situ with $4 \mathrm{ml}$ of formol-saline administered through a cannula. After fixation, tissues were embedded in paraffin wax, sectioned and stained with haematoxylin and eosin. To compare the severity of the lung lesions of immunosuppressed and immunologically normal hamsters, the amount of cellular infiltration was graded from 0 to 3 and expressed as a lesion score (Fernald et al., 1972). The degree of infiltration shown in fig. 1 represents a grading of 2.

\section{RESULTS}

Preparations of anti-hamster thymocyte serum (ATS), known to suppress cell-mediated functions, were used to investigate the importance of thymus- 
dependent lymphocytes in the development of pneumonia in hamsters infected with $M$. pneumoniae.

\section{Effect of immunosuppression on the recovery of $M$. pneumoniae}

Sixty hamsters, half of them immunosuppressed, were examined 14 days after infection. In two out of four experiments mycoplasmas were isolated in significantly greater numbers $(P=<0.001$ and $<0.01$; Student's t-test) from the lungs of immunosuppressed animals than from the lungs of those that were immunologically normal (table I). However, there was no difference in the

TABLE I

The effect of treatment with anti-hamster thymocyte serum (ATS) on the recovery of Mycoplasma pneumoniae from the respiratory tract of hamsters 14 days after infection

\begin{tabular}{|c|c|c|c|c|c|c|}
\hline \multicolumn{2}{|c|}{ Experiment } & \multirow{2}{*}{$\underset{\text { prepared }}{\text { ATS }}$} & \multirow{2}{*}{$\begin{array}{c}\text { Site } \\
\text { tested }\end{array}$} & \multicolumn{2}{|c|}{ M. pneumoniae isolations from } & \multirow{2}{*}{$\begin{array}{l}\text { P value for } \\
\text { numbers of } \\
\text { organisms } \\
\text { isolated }\end{array}$} \\
\hline number & $\begin{array}{l}\text { performed } \\
\text { at }\end{array}$ & & & $\begin{array}{c}\text { normal } \\
\text { hamsters }\end{array}$ & $\begin{array}{l}\text { immunosuppressed } \\
\text { hamsters }\end{array}$ & \\
\hline 1 & CRC & CRC & $\begin{array}{l}\text { Pharynx } \\
\text { Lungs }\end{array}$ & $\begin{array}{l}3 \cdot 5 \pm 0 \cdot 4^{*}(8 / 8) \dagger \\
4 \cdot 0 \pm 0 \cdot 4 \quad(4 / 8)\end{array}$ & $\begin{array}{l}3 \cdot 8 \pm 0 \cdot 3(11 / 11) \\
6 \cdot 3 \pm 0 \cdot 2(9 / 11)\end{array}$ & $\begin{array}{l}>0.1 \\
<0.001\end{array}$ \\
\hline 2 & CRC & CRC & $\begin{array}{l}\text { Pharynx } \\
\text { Lungs }\end{array}$ & $\begin{array}{ll}3 \cdot 2 \pm 0 \cdot 3 & (10 / 10) \\
4 \cdot 9 \pm 0 \cdot 4 & (10 / 10)\end{array}$ & $\begin{array}{l}3 \cdot 6 \pm 0 \cdot 3(9 / 10) \\
6 \cdot 1 \pm 0 \cdot 1(9 / 10)\end{array}$ & $\begin{array}{c}>0.1 \\
0.01\end{array}$ \\
\hline 3 & $\begin{array}{l}\text { Chapel } \\
\text { Hill }\end{array}$ & CRC & Lungs & $6 \cdot 3 \pm 0 \cdot 3 \quad(6 / 6)$ & $6.8 \pm 0.5(5 / 5)$ & $>0 \cdot 1$ \\
\hline 4 & $\begin{array}{l}\text { Chapel } \\
\text { Hill }\end{array}$ & $\begin{array}{l}\text { Chapel } \\
\text { Hill }\end{array}$ & Lungs & $6 \cdot 3 \pm 0 \cdot 3 \quad(6 / 6)$ & $7 \cdot 0 \pm 0 \cdot 2(4 / 4)$ & $>0.1$ \\
\hline
\end{tabular}

$\mathrm{CRC}=$ Clinical Research Centre.

* Geometric mean \pm standard deviation of number of organisms expressed as $\log _{10}$ colourchanging units per $\mathrm{ml}$ in experiments $\mathrm{CRC}$ at and as $\log _{10}$ colony-forming units per $\mathrm{ml}$ in experiments at Chapel Hill.

$\dagger$ Proportion of hamsters from which organisms were isolated.

number of organisms isolated from the throats of hamsters in either group and organisms were not isolated from blood, spleen, liver or brain of any of the hamsters.

\section{Effect of immunosuppression on lung lesions}

Pneumonia in immunologically normal hamsters infected with $M$. pneumoniae was characterised by peribronchiolar and perivascular cuffing by lymphocytes, as shown in fig. 1. The pneumonia in immunosuppressed hamsters was much less severe, as indicated by a reduction in the number of cells associated with the lesions (fig. 2). Furthermore, the lesion scores for immunosuppressed hamsters were significantly less $(P=<0.001$; Student's t-test) than those for immunologically normal animals (table II). In contrast to suppression of peribronchial infiltration, the extent of the bronchial exudate was not affected, although its character changed. Whereas immunologically normal hamsters 
had a bronchial exudate of polymorphonuclear (PMN) leucocytes and large monocytes, the PMN leucocyte component was reduced in the exudate of animals treated with ATS; many of the ATS-treated animals appeared to have bronchial exudates consisting of monocytes only. Control normal and immunosuppressed hamsters given inoculations of medium only did not develop lung lesions.

TABLE II

The effect of treatment with anti-thymocyte serum (ATS) on the lung lesions of hamsters infected with Mycoplasma pneumoniae

\begin{tabular}{|c|c|c|c|}
\hline \multirow{2}{*}{$\begin{array}{l}\text { Experiment } \\
\text { number* }\end{array}$} & \multicolumn{2}{|c|}{ Lesion scores for } & \multirow{2}{*}{$\begin{array}{l}\text { P value for } \\
\text { lesion scores }\end{array}$} \\
\hline & $\begin{array}{c}\text { normal } \\
\text { hamsters }\end{array}$ & $\begin{array}{l}\text { immunosuppressed } \\
\text { hamsters }\end{array}$ & \\
\hline $\begin{array}{l}1 \\
2 \\
3 \\
4\end{array}$ & $\begin{array}{l}1.4 \pm 0.4(4 / 4) \dagger \\
1 \cdot 7 \pm 0 \cdot 3(10 / 10) \\
2 \cdot 3 \pm 0 \cdot 2(6 / 6) \\
2 \cdot 3 \pm 0.2(6 / 6)\end{array}$ & $\begin{array}{l}0.4 \pm 0.3(2 / 6) \\
0.3 \pm 0.2(4 / 10) \\
0.5 \pm 0.2(3 / 5) \\
0.4 \pm 0.2(2 / 4)\end{array}$ & $\begin{aligned} & 0.05-0.1 \\
< & 0.001 \\
< & 0.001 \\
< & 0.001\end{aligned}$ \\
\hline
\end{tabular}

* The numbers refer to the same experiments as shown in Table I.

$\uparrow$ Number of hamsters with pneumonia/number challenged.

\section{Discussion}

We have already mentioned the observation that has led to the belief that delayed hypersensitivity contributes to the production of lesions in $M$. pneumoniae infections. Our present results indicate that a thymus-dependent function is concerned in the pathogenesis of pneumonia in the hamster, and are similar to those of Denny et al. (1972), who infected mice intranasally with $M$. pulmonis and immunosuppressed them by thymectomy and X-irradiation. In both studies, immunosuppression was associated with a reduction in the severity of lung lesions, and mycoplasmas multiplied slightly more in the respiratory tract of the immunosuppressed than of the control animals. However, isolation of $M$. pneumoniae organisms from non-respiratory sites of ATS-treated hamsters was not observed, whereas isolation of $M$. pulmonis from organs other than the lungs occurred in immunodeficient mice more frequently than in immunologically normal ones. The reason for this difference is not clear, but it may be that one or more of the following factors was responsible: (i) $M$. pulmonis organisms, present in undetectable numbers in extrapulmonary sites, were able to multiply in the absence of cellular defence mechanisms; (ii) because the hamster is not the natural host for $M$. pneumoniae organisms, these mycoplasmas are unable to multiply in non-pulmonary sites; and (iii) the ATS was not sufficiently immunosuppressive to permit extrapulmonary dissemination of the organisms in the hamster.

Although we have demonstrated the importance of thymus-dependent lymphocytes in the development of lung lesions in $M$. pneumoniae-infected hamsters, the role that these cells play in immunity is not known. Fernald et al. 


\section{MYCOPLASMA PNEUMONIAE INFECTION IN HAMSTERS}
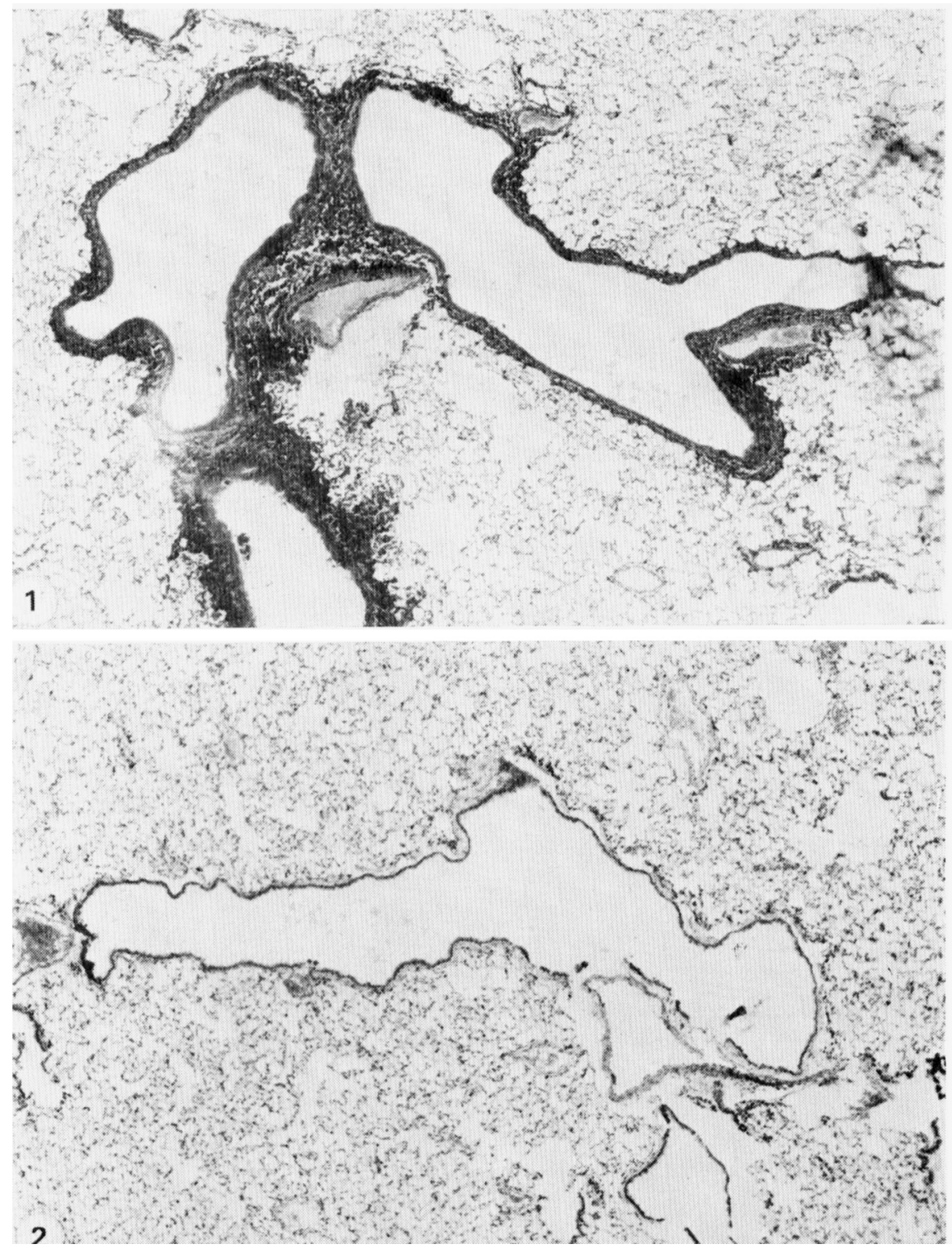

FIG. 1.-Vertical section of lung from an immunologically normal hamster 2 weeks after intranasal challenge with $M$. pneumoniae. There is peribronchiolar and perivascular cuffing by lymphocytes. $\times 45$.

FIG. 2.-Vertical section of lung from an immunosuppressed hamster 2 weeks after intranasal challenge with $M$. pneumoniae. There is minimal lymphocyte infiltration. $\times 45$. 
(1972) have shown that the hamster-lung lesions comprise two distinct populations of lymphocytes, one of which contains immunoglobulin while the other does not. Hamsters develop lung lesions more rapidly on re-infection than on primary infection. Thus, the lesions are most extensive three days after infection and have resolved by day 14, a time when lesions are normally prominent. The predominant cell in these accelerated lesions is immunoglobulin-negative, and this suggests that cell-mediated, rather than antibodymediated, mechanisms are major factors in immunity to $M$. pneumoniae infections. However, there is now some evidence to indicate that, in man, local secretory antibody may also be a factor in resistance to re-infection (Brunner et al., 1973). Studies on infection of hamsters with $M$. pneumoniae after passive transfer of either serum or sensitised lymphocytes from immune hamsters may help to resolve the extent to which cell-mediated mechanisms play a part in resistance to $M$. pneumoniae infection.

\section{SUMMARY}

Intranasal inoculation of Mycoplasma pneumoniae into hamsters caused pneumonia characterised by peribronchial and perivascular cuffing by lymphocytes. Hamsters immunosuppressed by treatment with anti-thymocyte serum developed a much less severe pneumonia. The numbers of organisms isolated from the lungs of immunosuppressed animals were greater than those obtained from the lungs of immunologically normal animals but there was no evidence that extrapulmonary spread occurred. These results indicate the importance of cellmediated mechanisms in the pathogenesis of this mycoplasma-induced pneumonia. The hamster model may help to establish the role of cell-mediated immunity in resistance to this type of infection.

We thank Mr G. F. Heath and Mrs Sharon Veal for technical assistance, the staff of the Department of Pathology, Clinical Research Centre, for preparation of histopathology sections and Dr A. C. Allison for a supply of anti-thymocyte serum.

\section{REFERENCES}

Arai, S., Hinuma, Y., Matsumoto, K. and Nakamura, T. 1971. Delayed type hypersensitivity in hamsters infected with Mycoplasma pneumoniae as revealed by macrophage migration inhibition test. Jap. J. Microbiol., 15, 509.

Biberfeld, G. 1972. In Pathogenic mycoplasmas, edited by K. Elliott and J. Birch, Ciba Foundation Symposium, no. 6, new series, Amsterdam, p. 365.

Brunner, H., Greenberg, H., James, W. D., Horswood, R. L. and Chanock, R. M. 1973. Decreased virulence and protective effect of genetically stable temperature-sensitive mutants of Mycoplasma pneumoniae. Ann N.Y. Acad. Sci., 225, 436.

ClYDE, W. A. JR. 1964. Mycoplasma species identification based upon growth inhibition by specific antisera. J. Immun., 92, 958.

Dajani, A. S., Clyde, W. A. And Denny, F. W. 1965. Experimental infection with Mycoplasma pneumoniae (Eaton's agent). J. exp. Med., 121, 1071.

Denny, F. W., Taylor-Robinson, D. and Allison, A. C. 1972. The rôle of thymusdependent immunity in Mycoplasma pulmonis infections of mice. J. med.Microbiol., 5, 327.

FerNald, G. W. 1969. Immunologic aspects of experimental Mycoplasma pneumoniae infection. J. infect. Dis., 119, 255.

J. MED. MICRO BIOL.-VOL. 7 (1974) 
FerNald, G. W. 1971. Mycoplasma pneumoniae delayed hypersensitivity: skin tests in guinea pigs. Bact. Proc., p. 103.

Fernald, G. W. 1972. In vitro response of human lymphocytes to Mycoplasma pneumoniae. Infect. Immun., 5, 552.

Fernald, G. W., Clyde, W. A. ANd Bienenstock, J. 1972. Immunoglobulin-containing cells in lungs of hamsters infected with Mycoplasma pneumoniae. J. Immun., 108, 1400.

Leventhal, B. G., Smith, C. B., Carbone, P. P. And Hersh, E. M. 1969. Lymphocyte transformation in response to $M$. pneumoniae after experimental infection in man. In Proceedings of the Third Annual Leukocyte Culture Conference, 1967, edited by W. O. Rieke, New York, p. 519.

LeVEY, R. H. AND MedAwAR, P. B. 1966. Nature and mode of action of antilymphocytic antiserum. Proc. natn Acad. Sci. U.S.A., 56, 1130.

Mizutani, H., Kitayama, T., Hayakawa, A., Nagayama, E., Kato, J., NaKamura, K., TAMURA, E. AND IzUCHI, T. 1971. Delayed hypersensitivity in Mycoplasma pneumoniae infections. Lancet, 1, 186.

Taylor-Robinson, D., Denny, F. W., Thompson, G. W., Allison, A. C. And Mårdh, P.-A. 1972. Isolation of mycoplasmas from lungs by a perfusion technique. Med. Microbiol. Immun., 158, 9. 